\title{
A Statistical Analysis of Food fortification scheme
}

\author{
Dr. Parag Shah \\ Associate Professor, Dept. of Statistics, H L College of Commerce, Ahmedabad -9. Email:pbs1374@yahoo.co.in
}

\begin{abstract}
Food Fortification Initiative was launched with the objective of eliminating the problem of wide spread malnutrition within the State of Gujarat. The aim was to penetrate all the households and bring about a change in the consumables being used. The State Government and its agencies, along with the private partners joined hands to launch this initiative.

The primary objective of the project was

- To study the awareness and acceptance level among consumers about the fortified wheat flour.

- To gauge the effectiveness of the initiative of fortification of wheat flour and recommend ways to improve their efficacy.

The scope of this project was restricted to Ahmedabad city and only wheat flour fortification scheme was considered out of different food fortification schemes.

A survey of 568 Public Distribution scheme (PDS) consumers, 23 PDS owners and 39 Chakki owners was undertaken in the city of Ahmedabad using multi stage sampling. After analyzing the data considering the objectives of the projects, observations and conclusions were made. Recommendations were given on the basis of the findings of the project to make the fortification scheme for effective and acceptable.
\end{abstract}

Keywords: Fortification, PDS.

\section{Introduction:}

The nutritional status of the population is one of the most important factors determining the quality and productivity of the population, which in turn affects our national productivity. In the long run, good nutritional status contributes to the social and economic development of the nation. Food fortification, i.e., the addition of nutrients to specific foods based on the dietary habits and nutritional status of the target population, is one of the most popular nutritional interventions for improving the population's health. Food fortification is a vast area which incorporates edible oil fortification, milk fortification, flour fortification, candy fortification, etc. I selected wheat flour fortification as a part of our study because it is one of the most pivotal and a complicated assignment taken up by the Government of Gujarat towards improving the malnutrition status of the people in the state. The rationale behind the selection of wheat flour fortification as a part of my study was the fact that for the Government of Gujarat it became a challenging endeavor in creating the awareness and increasing the acceptance level among the consumers.

Fortified wheat flour has been introduced at the Antyoday card holder's level. Moreover, the Nookad Chakkis have also been made a part of this program which would cater to all other categories of people who do not buy from Ration Shops. This initiative by the Government of Gujarat to fortify wheat flour at all levels has brought about an impact on several households. Hence, this became the basis of my study where the objective was to gauge the awareness and the acceptance level among both, PDS consumers and other consumers (those who do not buy from the PDS). Also, a major emphasis was given to the awareness and the acceptance level among other associated parties - Chakki owners, PDS Owners, Provision Store Owners.

\section{Methodology}

The scope of the project is confined to Ahmedabad city. The Food Fortification initiative by the Government of Gujarat includes Oil Fortification, Flour Fortification and Salt Fortification etc. I have catered to only Wheat Flour Fortification under Flour Fortification.

In our project, data collection was done through administered questionnaires. Secondary data used in our project includes various sources like reports; Government's published data such as reviews available with the Department of Food and Civil Supplies, magazines, newspaper articles, internet and others.

As per municipal corporation Ahmedabad city was divided into different zones and each zone was further divided into areas. Simple random sampling was used for selection of areas from each zone. From each area selected PDS shops were identified and consumers taking benefits of these shops were investigated for my study.

23 ODS owners, 568 PDS consumers and 39 Chakki owners were considered for the study. 
PDS Consumers

\section{Analysis And Findings}

Out of total surveyed consumers 540 consumers responded about the duration of their consuming flour.

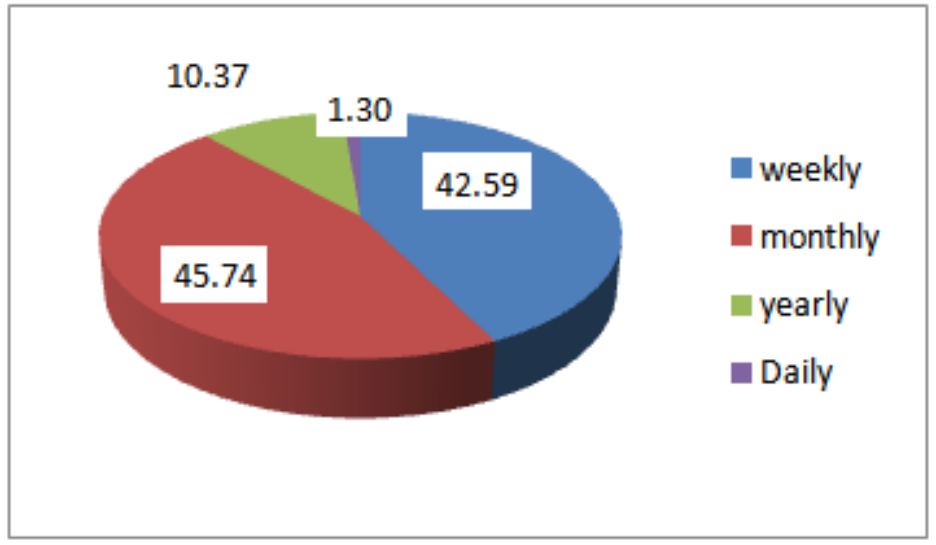

To know what type of flour and how do they get the flour of any type.

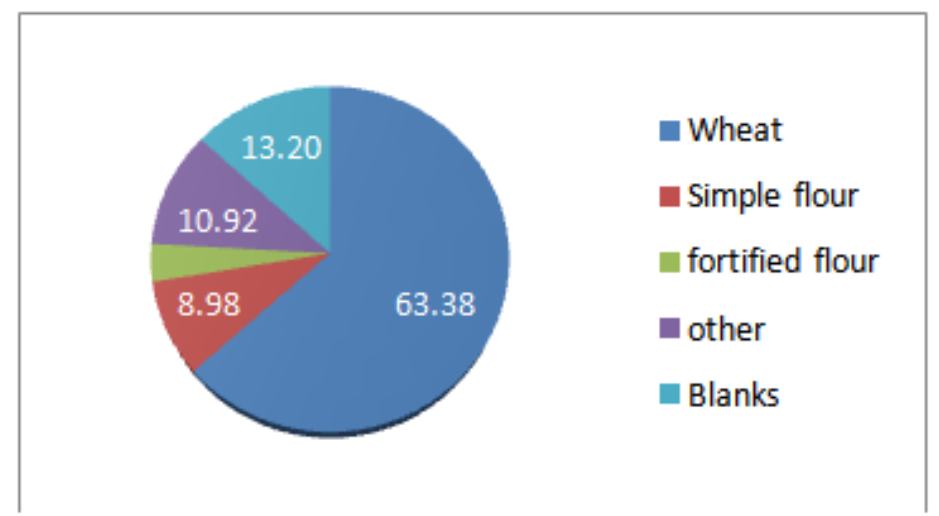

Most of the consumers who are surveyed are not aware of the benefit/ awareness about using fortified wheat flour.

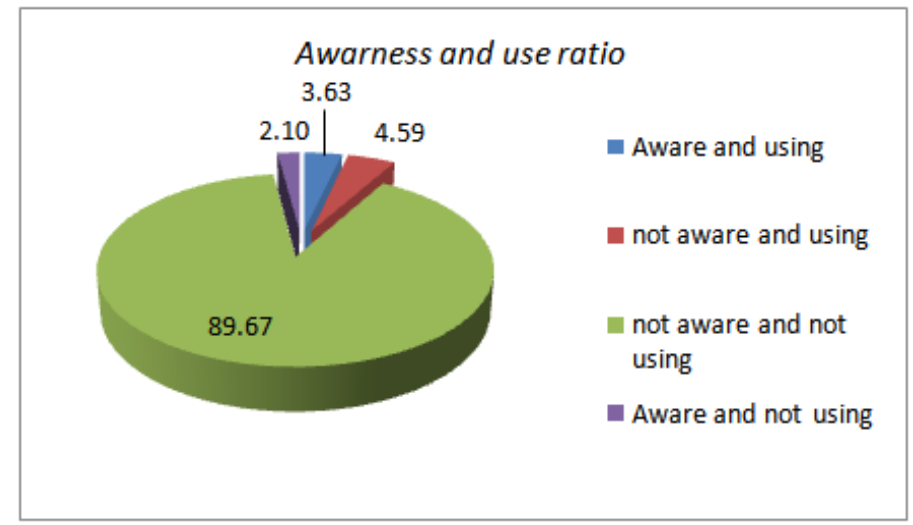

Those consumers who come under 'Not Aware and Using' category are those who use branded flour packs but are not aware whether Branded flour is fortified or not. Those who fall under the 'Not Aware and Not Using' category and consume Branded Wheat flour, fall under the Not Aware and Using category, i.e. 24 consumers (out of 523 - NA \& U) use Branded wheat flour. This implies that these consumers are Not Aware whether they are using fortified flour or not. 


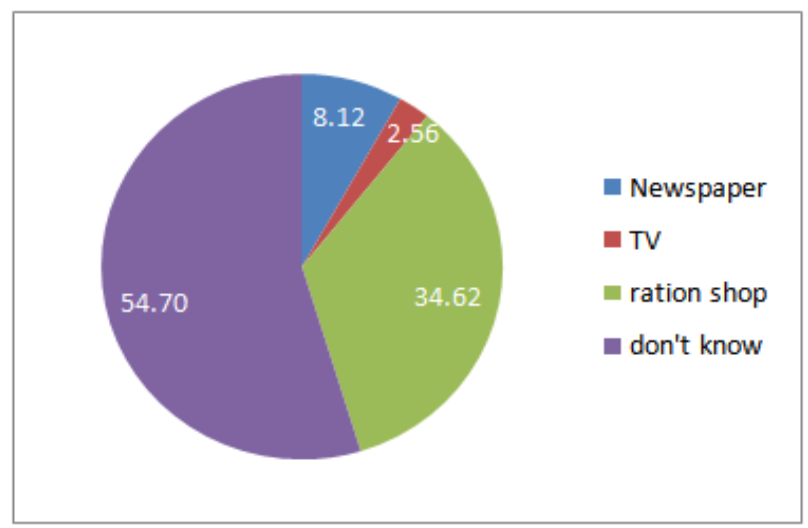

The main source from which the consumers came to know about fortified wheat flour includes ration shop. The second category is other which mainly includes articles in newspapers and television. However, only 19 consumers came to know about fortified wheat flour through Government Campaigns which should have been the major source of awareness.

510 out of 568 consumer surveyed are not aware about any government scheme of fortified flour. From the surveyed I tried to found which complains occurs at most while using fortified flour.

The consumers found the following differences in the Fortified Wheat flour:

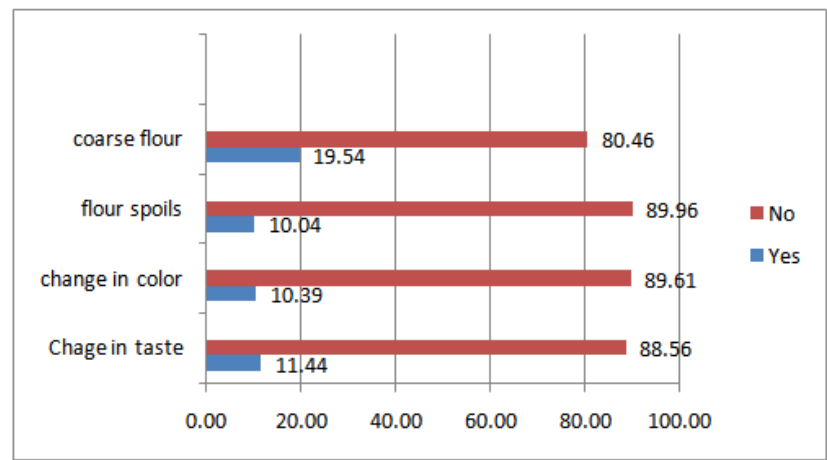

Survey suggest that almost $90 \%$ who are using fortified flour, have no complains about flour. But from those complains, $90 \%$ consumers complain about the flour spoils earlier.

\section{Chakki owner's - key Findings}

During Chakki owners' survey, we found many Chakki owners are aware about fortified flour. The data suggests from the surveyed Chakki owners, 59\% owners are aware of fortified flour.

Out of 39 surveys, we got the 29 customers for this finding:

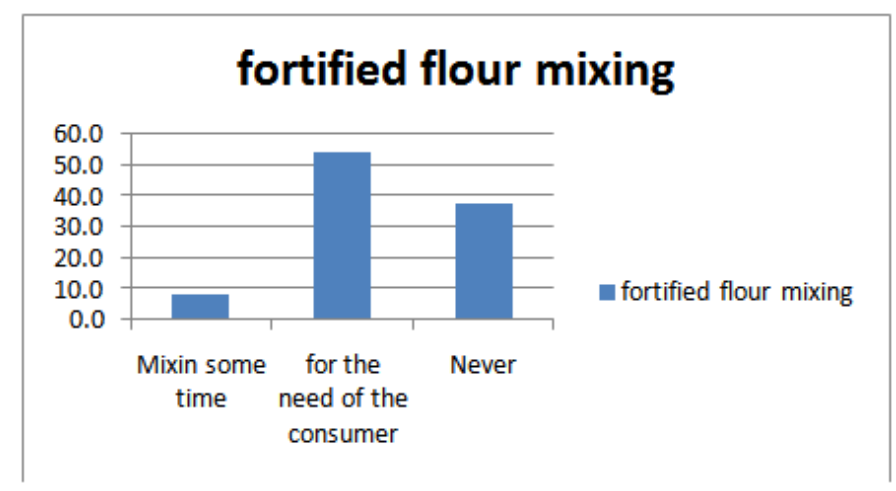

Above graph suggest that $55 \%$ of the Chakki owner mix the fortified, if there consumer wants to do so, while $35 \%$ never ask for mixing to their flour consumer.

The Chakki owners who are using and mixing flour got some complains from their flour consumer. From the surveyed Chakki owners, those who are aware and using fortified flour found some problems that they 
got to know from their customer who are using the flour. It shows that $25 \%$ of the surveyed consumer have the most complain about that the flour looks fat while similar ratio i.e. $25 \%$ of the surveyed Chakki owner, who are aware of flour type and using, do not have any complains for the flour.

$66 \%$ of the surveyed (out of 21 ) consumer mix the flour while grindings, which is a good ratio. While $33.3 \%$ do not mix due to reasons like: unawareness, customer do not want etc...

This findings suggest that if Chakki owners has given proper guidance of when to mix, how much to mix would be beneficiary in terms of awareness.

Most of the $49 \%$ owners get the information about this government scheme through newspaper. While $28 \%$ come to know while the survey process was going on.

Out of surveyed 39 owners 59\% are aware off fortified flour and they are also using them. Out of them 19 owners $(29 \%$ of users of flour, feel the difference between regular flour and fortified floor.

Almost all have the same complain about "flour became fat", while 15 owners have never found any difference in both the flour.

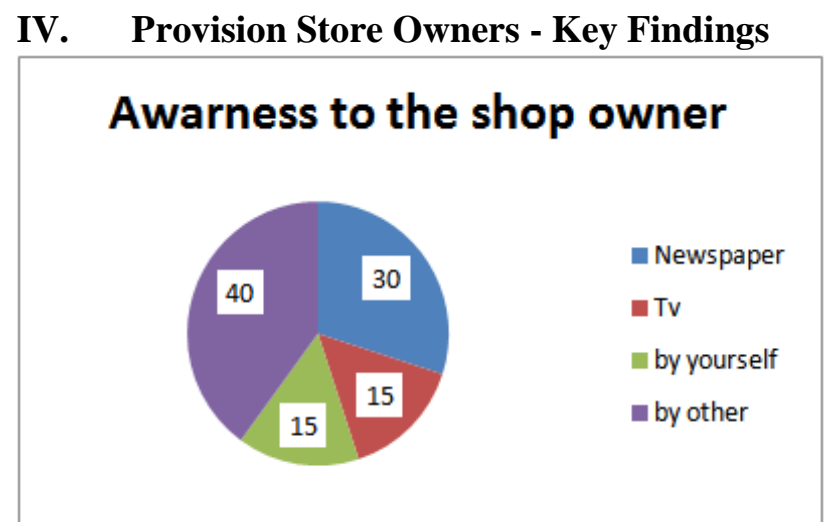

$44 \%$ of the provision store owners (out of 18) said that their consumers are aware about fortified wheat flour. A whopping 55.56\% of the provision store owners replied that their consumers would rarely or would not be aware about it at all. According to the responses received from some of the provision store owners, most of the consumers who consume the Branded wheat flour are themselves not aware whether they consume fortified flour or not.

Out of 7 owners who are aware about plan of government, 4 owners found this scheme useful to poor, while only 2 owners are not satisfied about the information through literature given to them by regular means.

Findings suggest that $78 \%$ shop owner believes that his consumers are not satisfied with the fortified flour. When the reason for not satisfaction is to be asked and almost 7 shop owner replied that the flour cannot stay for longer, while 5 shop owner replies that they are not aware of the benefits of such flour. Data suggest that almost no one shop owner is aware about the benefits of fortified flour like; increase in HB, or increase in strength, only 4 shop owner believes that it might be helpful in increasing protein.

\section{Conclusion}

A detailed study was undertaken to put an insight into the initiative of wheat flour fortification by the Government of Gujarat along with gauging the awareness and acceptance level of the end users of fortified wheat flour. Also, we assessed the role of all components of the supply chain - Nookad Chakkis, Provision Stores and PDS shops.

It has been observed that the awareness level at the consumers end seems to be low in the opinion of Chakki owners, Provision Store owners and PDS Shop Owners. 86\% of the consumers are not aware about fortified flour. The wheat flour fortification initiative has penetrated the State's PDS within a short span of time. But, $90 \%$ of the Antyoday consumers are dissatisfied with the substitution of wheat grains with fortified flour. But still the acceptance level among private consumers is considerably low and it is higher among Antyoday consumers.

When gauging the effectiveness of the fortification initiative, $100 \%$ of the Antyoday consumers are not aware whether they have experienced any health benefits or not. But it can also be the case that they may have experienced health benefits of which they are unaware, because the Antyoday consumers do not get their nutritional level measured.

PDS has supported the initiative of fortification and through its excellent distribution channels; it has acted as a medium of communication. But with the various levels of additions taking place in the supply chain, this was also the difficult part of the program. Although the Nookad Chakkis can contribute significantly in 
catering to a large proportion of the population to consume Fortified wheat flour, an adequate demand pull will create the right balance.

All the elements relating to this initiative are strong and efficient, but to bring it to a self-sustainable stage, a synchrony among all the Government departments and the end users be developed.

\section{Recommendations}

- In phase II, Government had approached the Chakki owners to reach the urban consumers. Instead, the Government should first educate the consumers (not Antyoday consumer) about fortified wheat flour and its benefits -either through leaflets/flyers in vernacular language and advertisement in vernacular/English newspaper. Consumers should be willing to come forward and enquire about fortified wheat flour. This would also mandate that the information relating to the availability of fortified wheat flour has reached the consumers.

- Results and Reports of the health benefits should be published regularly. Also, this fight for the hidden hunger should be brought to the notice of the masses through campaigns (for e.g. Save the Girl Child campaign). This approach would lead to long term benefits for this initiative.

- $\quad$ Fortified Wheat Flour sample packets should be made available for consumers at the Nookad Chakkis. This would ensure that the taste/smell/color issues are resolved from the root. Sales promotion i.e. through stalls at Provision stores would also be beneficial.

- Development of educational and training material for different level functionaries and the community is one of the important activities that should be undertaken. The educational/training material should be produced in the regional language and distributed widely throughout different areas of the city. NGOs should be made a part of these drives. They would be able to cater to the target population in an effective manner.

- The consumers grind wheat at home. Hence, these consumers are out of reach of the Phase III of the Government programme. The programme should then cater to these consumers by introducing premix sachets at the provision stores - i.e. bring it to the retail level. Also, if these consumers are given utensils of a required capacity and a 'List of instructions', then the addition of premix would be possible at homes also.

- Advertisements were released only during the implementation stages. There should be a consistency in screening advertisements on the local as well as national television using the Brand Ambassador.

- PDS shops and its functioning should be properly monitored. It should be ensured that the shop owners return the expired flour bags and procure the new ones. Due to the complication in the process of returning expired flour bags, many PDS owners happen to distribute the outdated flour bags which ultimately lead to dissatisfaction among consumers.

- For reaching the consumers who do not buy through PDS, Government of Gujarat should concentrate on launching an Atta brand. Brand Building and consistency in advertisements would lead to Brand recall. This could lead to greater acceptance as consumers perceive Branded Flour to be of better quality.

- As in case of Anganwadi, where children are provided with a onetime meal, some such agency should be developed which would ensure provision to Antyoday consumers with a onetime meal of fortified foods. It would be an essential step as the interview suggests that Antyoday consumers do not have the necessary resources to obtain and cook food.

\footnotetext{
[1]. "Food Fortification - A Gujarat Initiative by Food Civil Supplies and Consumer Affairs", Dept. of government of Gujarat.
} 